\title{
La autoficción, ¿un camino para cerrar heridas? El caso de Los otros Gondra
}

Fecha de recepción: 30/03/2020. Fecha de aceptación: 22/07/2020

\begin{abstract}
Resumen
En enero de 2019 se estrenó en Madrid Los otros Gondra (relato vasco) del dramaturgo vasco Borja Ortiz de Gondra, obra que indaga en las heridas de una familia vasca después de los largos años de violencia provocada por el terrorismo de ETA, la banda armada nacionalista. Conecta con otra obra del autor, Los Gondra (una historia vasca), pero mientras que ese drama analiza la trayectoria de esa familia durante más de cien años, Los otros Gondra disecciona las relaciones entre algunos de los familiares en un momento específico. El propio dramaturgo, que interviene también en la obra de actor, vuelve a su pueblo a recoger un premio literario, como efectivamente hizo en su día y la familia se encuentra obligada a enfrentarse con su historia reciente. El tema de la reconciliación en Euskadi (el País Vasco) se ha tratado en la novela y el ensayo, pero es novedosa su incorporación al teatro a través de la técnica de la autoficción.
\end{abstract}

Palabras clave: autoficción, convivencia, ETA, reconciliación, relato vasco, Ortiz de Gondra, Los otros Gondra (relato vasco).

\section{Is Autofiction a Way to Heal Wounds? The Case of Los otros Gondra (The Other Gondras)}

\begin{abstract}
In January 2019, The Other Gondras (A Basque Tale), written by the Basque dramatist Borja Ortiz de Gondra, premiered in Madrid. The work probes the wounds of a Basque family after the long years of violence caused by the terrorism of ETA, the armed nationalist group. It connects with another play by the author, The Gondras (A Basque Story), but while The Gondras analyzes the history of that family over more than a hundred years, The Other Gondras dissects the relationships between certain members of the family at a specific moment. The playwright himself, who also intervenes in the work as an actor, returns to his town to collect a literary prize, as indeed he did,
\end{abstract}


and the family is obliged to face its recent history. The theme of reconciliation in the Basque Country has been treated in the novel and the essay but its incorporation into the theatre through the technique of autofiction is novel.

Keywords: autofiction, co-existence, ETA, reconciliation, Basque tale, Ortiz de Gondra, Los otros Gondra (relato vasco).

\section{Introducción}

En 2016, la televisión vasca estrenó Las huellas perdidas, una serie de cinco documentales sobre la historia de Euskadi (País Vasco) desde 1960 hasta la declaración de ETA (Euskadi Ta Askatasuna, País Vasco y Libertad) del cese de la lucha armada de esta banda terrorista en 2011. Estos documentales incluían cincuenta testimonios, la mitad de anteriores terroristas y la otra mitad de víctimas del terrorismo y fueron un resultado directo del acuerdo entre la televisión vasca y el Gobierno Vasco como parte de su Plan de Paz y Convivencia. Este Plan, presente en su programa para 2016-2020, "Euskadi mira al futuro", tenía una extensa sección, "Paz, convivencia y derechos humanos", donde aborda los problemas actuales de la convivencia en el País Vasco.

En la presentación de Las huellas perdidas, el secretario vasco de Convivencia, Jonan Fernández, declaró que: "la política pública de memoria debe promover un proceso de participación y diálogo entre la ciudadanía de modo que se pueda resignificar desde el presente lo ocurrido en el pasado" (Landaluze). Luego se utilizaron los documentales como base para la confección de Herenegun (Anteayer), material didáctico para alumnos de la educación secundaria. En noviembre de 2018, numerosas asociaciones de víctimas del terrorismo y fundaciones exigieron la retirada de ese material por: "ofrecer [...] una visión sesgada, carente de todo rigor, que alimenta la teoría del conflicto, en un claro intento de blanquear la actividad terrorista de ETA" (Gil). Por otra parte, María Jiménez, investigadora de la Universidad de Navarra, declaró que: "Llama especialmente la atención la ausencia de referencias a los amenazados y extorsionados, los desterrados o los escoltas. Toman la palabra las víctimas más cercanas a la postura del Gobierno Vasco y se obvia a las más combativas" (Ormazabal).

En enero de 2019, después de una reunión con el Consejo Vasco de Participación de Víctimas del Terrorismo, dijo Fernández: "El pasado nos duele y nos divide intensamente todavía. Lo sabíamos y hemos vuelto a comprobarlo" (Gorospe). El periodista Luis R. Aizpeolea ha subrayado la importancia de impartir clases sobre el terrorismo de ETA: "para que sirva como inicio desde las aulas de una memoria crítica del pasado terrorista en Euskadi" (Aizpeolea). Argumenta que es especialmente necesario hacer esto dada, según diversas encuestas, la ignorancia de los jóvenes universitarios vascos sobre el pasado reciente. Puesto que todos los partidos vascos, salvo el PNV (Partido Nacionalista Vasco), rechazaron estos materiales, el Gobierno vasco los revisó y no se han impartido en los colegios hasta el curso académico 2019-2020.

\section{Ortiz de Gondra y la literatura como elemento sanador}

Borja Ortiz de Gondra, dramaturgo vasco nacido en 1965 y residente largos años en París y Nueva York, discrepa en parte de esta propuesta del Gobierno Vasco, consciente de que su opinión puede resultar radical. Aunque reconoce que los historiadores tienen su papel, afirma que: "no es el trabajo de los historiadores el que nos va a ayudar a vivir. Los historiadores pondrán claridad en lo que pasó, pero lo que nos va a ayudar a vivir y a superar ese pasado es la ficción" (Vicente, Álvaro). Dice que esta es la razón por la que obras como la novela Patria, de Fernando Aramburu, El 
comensal de Gabriela Ybarra, y otras han tenido tanto éxito. "Un historiador no puede contar el mecanismo emocional que ha llevado a hacer ciertas cosas o a perdonarlas, pero la ficción sí, y en ese sentido creo que leer Patria es mucho más sanador que tres tomos de Historia" (Vicente, Álvaro). La ficción, insiste, llega más al corazón de las personas que unos fríos datos históricos y les ayuda a entender el dolor que causó la violencia. Eso es especialmente importante, insiste, para llegar a los jóvenes, el futuro del país, que no conocieron esa época de la historia de Euskadi y, como muestran las encuestas, tienen unos conocimientos deficientes de esos años. En un coloquio televisivo insiste de nuevo en la importancia de la literatura para intentar comprender la historia reciente:

\begin{abstract}
Hay mucha hambre de ficción que nos lleve directamente al corazón de esos personajes que son, a lo mejor, incomprensibles, pero que tenemos que entender por qué llegaron a hacer eso, aunque no lo justifiquemos y eso nos permitirá dar el paso adelante para poder por fin mirarnos a los ojos y decir, 'es tan humano como yo' (Gárate Oronoz).
\end{abstract}

Con esta polémica de fondo, en enero de 2019, el mismo mes de la reunión del secretario de Convivencia del Gobierno Vasco con el Consejo Vasco de Participación de Víctimas del Terrorismo, Ortiz de Gondra estrenó su drama Los otros Gondra (relato vasco) en el Teatro Español de Madrid, galardonado con el Premio Lope de Vega del Ayuntamiento de Madrid. El autor aclara que las palabras, (relato vasco), no están por casualidad ni se trata de un asunto banal. Afirma: "Los vascos estamos ahora mismo inmersos en lo que se llama la batalla del relato, cómo vamos a contar lo que pasó y qué vamos a contar" (Vicente, Álvaro).

\title{
¿Autobiografía o ficción?
}

El año anterior a Ortiz de Gondra le fue otorgado el Premio Max por Los Gondra (una historia vasca), obra que repasa en tres actos la historia de cinco generaciones de una familia y en la que aparece el dramaturgo como actor. Los otros Gondra, relacionado con esa primera obra, no es una continuación, sino una pieza independiente. En vez de tres actos, consta de dieciséis escenas y solo seis personajes, dos de los cuales resultan ser Borja Ortiz, uno de ellos el dramaturgo de verdad y el otro Jesús Noguero, un actor vasco que hace de Borja.

Este hecho sugiere que Los otros Gondra esté basado en la autobiografía del dramaturgo y hay similitudes entre el drama y la vida del autor que parecen confirmarlo. Tanto el Borja de verdad como el del drama vuelven a su casa en Algorta, en el municipio de Getxo (Vizcaya), después de varios años en el extranjero para recibir un premio del Ayuntamiento por su labor teatral. Efectivamente, en 2017, el dramaturgo recogió el Premio Aixe Getxo por su drama Los Gondra. El galardón, en la realidad como en Los otros Gondra, tiene forma de molino en homenaje al molino del siglo XVIII que se encuentra en Getxo. En este molino abandonado, dice el personaje de Borja en el drama, jugaba él de niño y le contesta la madre que ahora se ha convertido en un restaurante de lujo, como efectivamente, ha sido.

No obstante, estas coincidencias con la vida real del dramaturgo, la obra no es autobiográfica. En el mencionado coloquio televisivo el autor habló de su visita a Algorta: "Lo que pasa después mezcla lo que pasó, lo que pudo pasar, lo que hubiera querido que pasara y lo que no pasaría nunca y hacemos un juego con el espectador en el que le pedimos lo que dice muy bien mi alter ego, Jesús Noguero, si no pasó, ocurre en el teatro" (Gárate Oronoz). Más adelante afirma: "Nada de esto pasó a mi familia (...) 
pero le podia haber pasado y mi lugar ha sido ponerme en la piel del otro, empatizar con esa gente a la que sí le paso" (Gárate Oronoz).

\section{El papel de la mujer vasca}

El Borja Gondra del drama quiere aprovechar su vuelta a la casa familiar para entrevistar a distintos miembros de su familia con la finalidad de crear teatro documental. Piensa que así podrá desvelar los secretos que abundan en su familia, pero no cuenta con el beneplácito de su madre para quien: "Eso de la literatura no sirve para vivir. La vida es otra cosa" (Ortiz de Gondra, 179). Para la madre, su hijo dramaturgo desde niño ha sido un mentiroso y, de mayor, monta dramas en el teatro que también contienen mentiras:

MADRE. Te inventas esas historias que escribes para el teatro y luego te las crees. Pero nosotros nos quedamos aquí.

BORJA. Por eso quería entrevistaros. Para que os escuchen directamente a vosotros, sin intermediarios, sin nadie que interprete lo que sentisteis. Se llama teatrodocumento (Ortiz de Gondra 178).

Una fuerte mujer vasca, la madre significativamente no tenía nombre en el drama estrenado en Madrid, convirtiéndose así más bien en una madre universal. Curiosamente, aunque en la obra puesta en escena en el Teatro Español aparece la madre en el reparto sin nombre, en la versión impresa del drama publicada hacia finales de septiembre de 2019, o sea, más de ocho meses después del estreno, figura con el nombre de Natalia (Ortiz de Gondra, 168). Nos parece que esto de alguna manera quita algo de la universalidad del personaje, aunque la madre de Borja sí aparece como "Natalia" en Los Gondra (una historia vasca).

La madre se lamenta de que sus dos hijos varones no le hayan dado nietos. Juan Manuel, ya fallecido, fue un empresario extorsionado durante años por ETA y a causa de esta tensión, abandonado por Blanca, su mujer; mientras que el otro, Borja, es homosexual y, a disgusto de la madre, casado con otro hombre. Tanto en la edición impresa como en la versión teatral hay un soliloquio de Borja antes de la primera escena en el que explica que el 25 de mayo de 2017 volvió a su pueblo, Algorta, para recibir un premio. Sin embargo, en la edición publicada figuran unas palabras que no se pronunciaron en el teatro: "Allí entre el público, estaba mi familia, finalmente orgullosa de algo que había hecho yo. Y junto a ellos, por primera vez, Matthew, mi marido" (Ortiz de Gondra, 169. Véase el soliloquio original en: https://www.youtube. com/watch?v=ugB66CQOlGg, consultado el 18 de enero de 2019)

La madre de Borja, sin embargo, no es la única madre que destaca en el drama por su independencia, su defensa a ultranza de la familia y su coraje. Ainhoa, prima de Borja y miembro de los otros Gondra, es madre adoptiva de Edurne, una niña africana, objeto de burla de parte de los vecinos por su forma de hablar euskera, la lengua vasca. Ainhoa tuvo que aguantar incluso que la madre de Borja dijera, al adoptar a la niña, que se estaba mezclando con las razas inferiores. Izaskun, la madre de Ainhoa, también fue otra madre de armas tomar. Activista de ETA y torturada por la policía, acabó exiliada en Cuba, donde murió y fue enterrada. Llamada "Izaskun" en la versión teatral, la madre de Ainhoa se llama "Itsaso" en la obra publicada (Ortiz de Gondra 232). Sin embargo, hay varias referencias a ella como "Izaskun" en Los Gondra (Ortiz de Gondra 70,74-5, 97, 137).

En un coloquio el 31 de enero de 2019 en el Teatro Español en el que participaron el dramaturgo, el director Josep María Mestres, varios de los actores y moderado por la 
escritora Almudena Grandes, se resaltó esta llamativa preponderancia en el drama de la figura de la madre fuerte y el hecho de que no aparecen padres, a diferencia de la primera obra, Los Gondra. El propio autor también llamó la atención sobre el nombre del personaje/alter ego, Borja Gondra, siendo este el apellido de su madre y no de su padre. Una de las facetas, pues, de esta obra parece ser un homenaje a la madre vasca. Este es el sentir de Cecilia Solaguren, la actriz que encarnó el personaje de Ainhoa y dijo, a mediados de enero en el mencionado coloquio televisivo: "De alguna manera, hay un homenaje a las madres. Yo creo que la madre vasca, la mujer vasca, es una mujer muy poderosa y creo que en esta obra está muy claro" (Gárate Oronoz).

\section{Las heridas de la familia}

El drama se mueve entre significativos acontecimientos del pasado y la situación familiar actual. Los eventos del pasado no se explican del todo, creando así un ambiente de misterio. A lo largo de la obra, se indaga en las frágiles relaciones entre varios miembros de esa familia por las heridas sostenidas en los llamados años de plomo. Borja y su madre se encuentran actualmente con un dilema. Se acaba la concesión de la sepultura familiar en el cementerio local y deben decidir si renovarla o no. Si no lo hacen, irán los restos a una fosa común. Ainhoa complica esta decisión al querer traer los restos de su madre de Cuba para enterrarlos en la sepultura donde están los de Juan Manuel, víctima precisamente de la extorsión de ETA que le exigió repetidamente el impuesto revolucionario a través de treinta y cuatro cartas que encontró su madre después de su muerte.

En la edición publicada se mencionan veintiocho cartas. Dice la madre: "Y fui yo quien encontró la caja en su armario, y quien la abrió, y quien leyó las cartas una por una. Veintiocho en total. Cada una con su fecha. Una vez al mes" (Ortiz de Gondra 198). Al final de la obra, tanto en la versión publicada como en la representación teatral, Borja, el dramaturgo, quema una carta frente al público: "Yo saco una carta de la carpeta. Enciendo un mechero. Acerco la llama a la carta, que empieza a arder. Una carta en cada función. La cuenta atrás hacia el silencio definitivo. Hacia el olvido. Y tal vez, por fin, el perdón" (Ortiz de Gondra 241). En Madrid, hubo treinta y cuatro funciones de esta obra en 2019 y de ahí, las treinta y cuatro cartas.

ETA no mató a Juan Manuel, pero sufrió una muerte civil, ya que los vecinos se enteraron de que estaba en el punto de mira de la organización terrorista por aparecer un día sus iniciales en una diana en el frontón. A raíz de esto, dejaron de hablarle, unos por miedo y otros porque pensaban que no pagaba el impuesto revolucionario. El frontón, el lugar donde empezó esta división entre los Gondra y los otros Gondra, es un elemento tan central en el drama que está permanentemente a la vista de los espectadores en el escenario y es donde se realiza toda la acción. Resulta que la diana con las iniciales que tanto sufrimiento causó en la familia de los Gondra la pintó precisamente Ainhoa, prima de Juan Manuel.

Esta imagen llamativa de la diana, desgraciadamente demasiado conocida durante los años del terror, aparece también en la novela Patria de Fernando Aramburu donde unos días antes de que ETA mate en la calle a Txato, aparece una diana con su nombre en el quiosco de la plaza del pueblo, una costumbre de ETA que ha sobrevivido incluso hasta hoy. En abril de 2019 aparecieron en el pueblo vizcaíno Erandio, unas pintadas de una diana con las siglas del Partido Popular (PP) dentro y debajo, "Gora (Viva) ETA" (Europa Press). A Txato, como a Juan Manuel, le extorsiona la banda terrorista, enviándole cartas. Al principio piensa que, pagando el dinero, le dejarán en paz, pero piden cada vez más hasta que ya no lo puede pagar. Como en el caso de Juan Manuel, el pueblo se entera de que están extorsionando a Txato y sufre una muerte 
civil: "se quedó más solo que la una. ¿Los amigos? No los buscaba, no lo buscaban. Lo aislaron al mismo tiempo que él se aisló" (Aramburu, 211). Incluso cuando muere asesinado, los vecinos lo ningunean, evitando ir a su entierro y procurando no hablar con Bitorri, su viuda. Al contrario que Aramburu, Ortiz de Gondra no nombra a ETA en el drama y explica la razón:

En la obra nunca se dice ni quién enviaba las cartas, ni qué decían las cartas, ni cuál era la organización, (...) porque creo que eso nos llevaría a un lugar documental, y porque hay algo que me da un inmenso pudor y un inmenso respeto y es que hay víctimas del terrorismo que pueden hablar en primera persona, porque realmente sufrieron el terrorismo en sus carnes. Yo no puedo hablar en primera persona, a mí no me ha pasado nada, pero sí puedo ser muy solidario y entender mucho lo que pasó y ponerme en el lugar de lo que pasó (Vicente, Álvaro).

\section{La búsqueda de la universalidad}

Hay otra razón, sin embargo, que tiene más que ver con la naturaleza de la creación literaria. Dice que, aunque la obra se refiere a un lugar y a unas circunstancias muy particulares: "al mismo tiempo, lo que quiero hacer es teatro y quiero tocar algo mucho más universal, que pueda reconocer cualquiera y que hable de cómo podemos cerrar esas heridas" (Vicente, Álvaro). La violencia, afirma, se encuentra en todas partes del mundo y para él, es intrafamiliar, "es decir, aquí no venía nadie de fuera a explotarnos ni a invadirnos, simplemente unos Gondra hacían unas cosas a otros Gondra". Precisamente por eso piensa que la obra puede tener significado para personas en otras partes del mundo que hayan sufrido algo similar al conflicto vasco y, de hecho, le han llegado a decir que tiene semejanza con lo que pasó en los Balcanes. Si hay elementos en la obra no del todo claros para un público no especialmente familiar con los acontecimientos en el País Vasco, parece que se debe a una decisión consciente del autor y su búsqueda de la universalidad: "Cuando tienes la voluntad de no hacer un documento, tocas algo universal, y al mismo tiempo, no deja de ser super reconocible, porque a la gente que sepa lo que pasó, puede ponerle cara y nombre a todo lo que cuento, pero yo no, creo que mi misión es dejarlo en esa ambigüedad en la que se puede entender" (Vicente, Álvaro).

Es en este afán de universalidad donde encaja Edurne, la hija adoptada de Ainhoa. De raza africana, y sin una gota de sangre de los Gondra, resulta que, paradójicamente, Edurne representa el futuro de la familia cuyo apellido lleva. Tanto la madre como Borja llegan, al final, a una reconciliación con "los otros Gondra" y la madre cuenta a Edurne que ha decidido no renovar la concesión de la sepultura. En vez de esto, le ha dejado una suma de dinero en su testamento para que compre otro espacio en el cementerio, lo más cercano al mar, y que las lápidas de los Gondra no lleven ni nombres ni información sobre los muertos. Ella, que ha luchado denodadamente por la familia y es la última en reconciliarse con los otros Gondra, no quiere ser enterrada allí, sino que sus cenizas se arrojen al mar, alcanzando así la paz.

La elección de Fenda Drame, una actriz negra de familia maliense, para encarnar a Edurne parece que fue del director de la obra, Josep María Mestres, ya que el dramaturgo solo especificó que no fuera una actriz blanca (Vidales). Para algunos críticos esta elección de una actriz africana es un acierto y constituye una metáfora. Dice Miguel Ayanz: "Una chica negra, hija adoptiva de Ainhoa, habrá de cargar con el peso del odio que se hereda en la familia, por más que aquello le sea indiferente tanto por sus raíces reales como por su edad. Una gran metáfora de los absurdos a los que lleva el nacionalismo, el independentismo y la violencia" (Ayanz). Para otros, sin embargo, es una argucia que no funciona. Según José Catalán: "Fenda Drame 
encarna un personaje a todas luces discordante, la hija adoptada de la prima abertzale [partidaria del nacionalismo vasco], una adolescente de raza negra que quiere ser alegoría y metáfora, pero que realmente no pega ni con cola" (Catalán).

La decisión de Ortiz de Gondra de que Edurne no fuera blanca, no obstante, no fue banal ni un intento de llamar la atención. Lo explica así:

En una de mis visitas a las fiestas de Algorta, que es mi pueblo y el pueblo en el que se desarrolla la obra, me di cuenta de que buena parte de los niños que bailaban las danzas tradicionales era de origen asiático, africano, mestizo... Entonces me surgió la gran pregunta ¿qué querrían hacer ellos con un pasado que les pertenece y no les pertenece? (Vidales)

En el mencionado coloquio en el Teatro Español, Ortiz de Gondra volvió sobre este tema de Edurne. Confesó que en 2017 cuando volvió a Algorta para recoger su premio eran las fiestas de San Ignacio. En la plaza estaba bailando un grupo de niñas que llevaban el tradicional vestido vasco y cantaban en lengua vasca. Entre ellas había chinas y negras. Esto es lo que le dio la idea de que Edurne no fuera blanca, sino que representara la diversidad que existe hoy en el País Vasco y en España en general.

\section{El papel de la autoficción}

En este mismo coloquio se abarcó el tema de la autoficción, término acuñado por Serge Doubrovsky en el año 1977, aunque el concepto venía de mucho antes. Uno de sus exponentes más conocidos, el dramaturgo y crítico uruguayo Sergio Blanco, amigo, dicho sea de paso, de Ortiz de Gondra, explica la autoficción como:

el cruce entre un relato real de la vida del autor, es decir, una experiencia vivida por este, y un relato ficticio, una experiencia inventada por este. $Y$ lo interesante es que la autoficción no es ni una cosa ni la otra, sino la unión de las dos al mismo tiempo. Eso es lo que la vuelve fascinante. No estamos ante la disyuntiva de "ser o no ser", sino ante la certeza de "ser y no ser" a un mismo tiempo. Esto último es lo que hace que la autoficción proponga cuestionarse todo el tiempo sobre el vínculo entre lo que es verdadero y lo que es falso, es decir, el famoso tema de la frontera entre lo real y lo no real que siempre ha habitado el mundo del arte desde Sócrates hasta nuestros días (Blanco 22-3).

Según Blanco, hay quien critica a los autores de autoficción por vanidosos, pero, para él, es una forma de intentar comprender al otro:

la autoficción no es un encierro ególatra en sí mismo, como erradamente suele creerse, sino que es, por el contrario, un camino de apertura a los demás. Si bien la empresa autoficcional surge de un yo, de una vivencia en primera persona, de una experiencia personal (...), siempre va a partir de ese yo para ir más allá de ese sí mismo, es decir, para poder ir hacia otro (Blanco, 24).

Ese "ir hacia otro" es lo que pretende Ortiz de Gondra en Los otros Gondra. Viene, además, motivado en parte por un sentimiento de culpabilidad, ya que tanto el Borja de la obra como el Borja real se marcharon lejos del País Vasco en esos años tan conflictivos y no sufrieron las consecuencias de la violencia de primera mano. En el drama, esa culpabilidad queda plasmada en unas palabras de la madre a Borja:

Has vivido treinta años lejos, sin preocuparte un segundo por tu hermano ni por lo que ocurrió. Y de pronto te quedas sin inspiración, se te ocurre sacarnos en el teatro, 
tienes un éxito y ya te crees con derecho a decidir. Pues las cosas no funcionan así, hijo. Los que hemos estado siempre aquí hemos sido nosotros, sufriendo día a día cosas de las que tú ni te has enterado (Ortiz de Gondra 215).

Insiste Ortiz de Gondra, sin embargo, en que a pesar de eso, le duele la reciente historia de Euskadi tanto como a los que se quedaron: "Y tengo esa sensación de culpabilidad, de no haber estado allí, de no haber hecho lo que tenía que haber hecho y un poco la intuición de que la ficción, y a través del teatro, voy a poder contar algo que yo no podría hacer en la realidad" (Gárate Oronoz).

En enero de 2017, en vísperas del estreno de su obra anterior, Los Gondra, a la pregunta de que si quería con esa obra curar las heridas de su familia, contestó Ortiz de Gondra:

Las heridas que nos causan nuestras familias nunca se curan. Se arrastran a lo largo de la vida. Aprender a habitarlas es parte de la madurez. Pero para un escritor, ese dolor por el daño que nos hicimos es un filón inagotable y yo he querido bucear en él para tratar de entender por qué tuve que irme muy lejos del País Vasco y de mi familia para poder ser quien era (López Rejas).

A pesar de esto, como el Borja de Los otros Gondra, sabe que tiene que volver a sus raíces porque, "no puedo romper el vínculo que me ata a mi tierra, la conciencia de que por más que me aleje, un día volveré para ser enterrado allí" (López Rejas).

\section{El teatro y la interpretación de la historia}

Preguntado en 2019 en el programa televisivo "La hora cultural" por los orígenes de Los otros Gondra, contesta que después de escribir Los Gondra, le quedaba algo más por contar, pero sobre todo, quería plantear preguntas, ya que no es la función del teatro dar respuestas. Explica que al volver a Algorta, su pueblo, se dio cuenta de la división en la sociedad vasca entre los que quieren olvidar la época de violencia y los que no pueden, porque ese segmento de la sociedad:

piensa que no hay que pasar nunca la página porque no se pidió perdón y hasta que ese dolor no se reconozca, no se puede pasar la página. (...) Yo, personalmente, creo que debemos leer la página hasta el final pero una vez que la hayamos leído, habrá que pasarla. La función pregunta, ¿cómo se hace eso? No tengo respuesta pero espero que los espectadores la encuentren (Gárate Oronoz).

En la entrevista de 2017, Ortiz de Gondra subrayó la necesidad de revisar críticamente los últimos cincuenta años de la historia del País Vasco y su convencimiento de que los escritores, a través de su ficción, pueden ayudar con esta tarea. Reconoció ya entonces, sin embargo, que existía todavía una parte importante de la población que no quería hacer esa revisión, sino simplemente, "pasar rápidamente la página sin leerla", algo que vuelve a recalcar dos años después. No obstante, ahí es donde tiene un papel importante la ficción:

Por eso pienso, como creador, que es el momento de que la ficción se interrogue sobre quiénes hemos sido y quiénes somos hoy. En la batalla por el relato que se comienza a vivir ahora, es fundamental que el imaginario colectivo se pueble de ficciones que respondan a una pluralidad de voces; tal vez la mentira de la ficción nos ayude a digerir la verdad de la vida (López Rejas).

Jesús Noguero, que encarna al propio Borja Gondra en la obra, piensa que este insinúa un camino que tiene que ver con el dolor, con una capacidad de reconocer el propio 
dolor y ser capaz de mostrar el propio dolor al otro y "a partir de ahí, a lo mejor podemos empezar a hablar, a mirarnos y encontrarnos en algún lugar" (Gárate Oronoz).

En una escena de la obra aparecen la madre, Juan Manuel, su hijo muerto, Borja, el alter ego del dramaturgo, y este. El dramaturgo ha leído las cartas de los terroristas a Juan Manuel que ha guardado su madre en una caja y pregunta: “¿Qué debo contar yo de todo aquello?" (Ortiz de Gondra 217). No recibe respuesta. Consciente de que, debido a sus largos años de ausencia, no conoce realmente el sufrimiento de su hermano pregunta a Juan Manuel: "¿Qué derecho tengo entonces a inventar tu dolor y tus palabras; a pergeñar una escena que tal vez nunca ocurrió?" (Ortiz de Gondra 218). La contestación se la proporciona Borja (Jesús Noguero): “Ocurrirá en el teatro, y con eso basta. Se llama autoficción, tú mismo lo has dicho: eso que nos ayuda a vivir. No estuviste allí. No viste a tu hermano convertido en el fantasma de sí mismo: un hombre vencido de cincuenta y cinco años. Escribe y expía esa culpa" (Ortiz de Gondra 218).

Por su parte, el dramaturgo hace hincapié en que la obra no trata exclusivamente de un tema vasco con el que el público puede o no estar familiarizado, sino de un tema universal: "Cuando uno habla del corazón de la gente, habla de lo universal. Creo que se entenderá mucho su clave vasca, pero va a llegar a gente que no sepa nada de esto porque habla de como los seres humanos pueden mirarse a los ojos y reconocerse como seres humanos" (Gárate Oronoz).

\section{El compromiso con los jóvenes}

En su artículo, "Geografía de la neutralidad", Eduardo Madina comenta el nuevo programa del Gobierno Vasco, Etikasi 2019 ("aprender ética") que pretende educar a los jóvenes vascos en los derechos humanos. Según el Gobierno Vasco se trata de, "consolidar un proyecto educativo en derechos humanos, basado en el fundamento humano de la dignidad humana, y orientado al compromiso con la paz, la diversidad y la solidaridad, desde la opción por la empatía" (Anónimo). El objetivo de este ambicioso proyecto, que depende del Consejo de la Juventud del País Vasco y de la Secretaría General de Derechos Humanos, Convivencia y Cooperación del Gobierno Vasco, "es generar herramientas educativas y reforzar las interacciones socioeducativas frente a los retos pendientes y emergentes de la convivencia" (Anónimo).

Los estudiantes que participen en este programa, inaugurado en junio de 2019, se familiarizarán con los horrores del nazismo mediante visitas a Auschwitz y otras ciudades europeas que tuvieron campos de concentración, pero también irán a "regiones azotadas por graves episodios de violencia como Irlanda del Norte" (Anónimo). Se argumenta que este contacto físico con sitios en el extranjero donde tuvieron lugar episodios tan traumáticos causará un impacto muy fuerte en los alumnos y facilitará un recuerdo permanente de esa experiencia. Los organizadores sostienen que este programa "permite ponerse en el lugar de otras personas y ver el mundo desde otro lugar" (Anónimo), o sea, implica el desarrollo de la empatía, el "ir hacia otro" que describe Blanco relevante a la autoficción. Sin embargo, en este caso resulta ser un ir hacia otro fuera de España. No deja de tener cierta ironía que mientras un primer grupo de estudiantes vascos ha ido a Auschwitz, otro ha visitado Belfast, zona de gran violencia en el pasado. Allí, lejos de su país, se pedía a estos jóvenes que procedían de una región igual de "azotada por graves episodios de violencia" que Belfast, que se pusieran "en el lugar de otras personas".

Aunque Madina, nacido en Bilbao en 1976, reconoce los méritos de este programa, dice que no recuerda ni una sola ocasión, "en la que un profesor del colegio en el 
que estudié nos explicara qué era ETA y por qué no podia ser admitido el asesinato de seres humanos" (Madina). Admite que esto no ocurría solamente en el ámbito escolar, sino en la sociedad vasca en su conjunto, donde reinaba un silencio sobre las atrocidades del terrorismo y la gente miraba para otro lado, como si no pasara nada. Recuerda Madina que durante la Segunda Guerra Mundial salían de noche desde Italia trenes con miles de deportados que acabarían en los campos de concentración nazis en Polonia. Tenían que atravesar el largo túnel de San Gotardo bajo los Alpes suizos y lo hicieron gracias a un acuerdo entre la Alemania nazi y Suiza, un país neutral. Esta neutralidad, que no quiso ver que, al permitir pasar los trenes con los detenidos, cooperaba con el exterminio nazi, la compara Madina con el silencio que ha reinado durante tantos años en el País Vasco: "Cinco largas décadas de violencia terrorista que solo fueron posibles gracias a que en nuestras ciudades y nuestros pueblos también había túneles de San Gotardo; vascos que nunca vieron nada, que miraron para otro lado, que nunca plantaron cara a ETA" (Madina). Piensa que ya es hora de terminar con ese silencio y "reconocer que hubo un tiempo en que la ética no operaba en amplios sectores de la sociedad vasca" (Madina).

\section{La obligación del teatro de matar el silencio}

Los otros Gondra lucha en el escenario contra ese silencio. Muy al principio de la obra, Borja y su madre, Natalia, discuten sobre si es aconsejable o no mantener ese silencio sobre los dolorosos acontecimientos del pasado. Mientras que la madre es partidaria de no romper el silencio, Borja opina que es fundamental hablar de las cosas para que no se cometan similares errores en el futuro:

BORJA. Si os doy la oportunidad de hablar, optáis por callaros. Y si escribo yo vuestras palabras, me acusáis de inventar.

NATALIA. La gente normal preferimos el silencio.

BORJA. Os habéis callado treinta años. ¿Qué digo? Nuestra familia se ha callado cien años, como todo este pueblo.

NATALIA. Callados es como hemos podido sobrevivir.

BORJA. En el silencio, los secretos se pudren, ama.

NATALIA. Así debe ser: silencio y secreto, hasta que las cosas dejen de doler.

BORJA. Y la siguiente generación repita el error (Ortiz de Gondra 178).

Ortiz de Gondra y Borja, el personaje, están convencidos de que el sacar a la luz el dolor y las heridas causadas en esa familia (que es y no es la del dramaturgo) por la historia reciente del País Vasco, facilitará la comprensión del otro y eventualmente, el perdón. Solo así es posible la sanación de las heridas y una auténtica reconciliación.

En la última escena de la obra, "Postdata", aparece el dramaturgo en el escenario con una carpeta que ha recibido en Nueva York varios meses después de volver de su viaje a Algorta. El paquete contiene las cartas de su hermano y una nota de Ainhoa. Le informa que tanto ella como Edurne han leído las cartas de Juan Manuel y quieren que las conserve Borja. En el revés de la nota hay una palabra que solo ha podido escribir Ainhoa después de que todos los miembros de la familia hayan sido capaces de enfrentarse con el pasado, verbalizar su dolor y reconocer cada uno su parte de culpabilidad: "Perdón” (Ortiz de Gondra 240).

Dice Sergio Blanco, "En esta búsqueda del amor del otro, es claro que el objetivo de la producción autoficcional no es enclaustrarse o recluirse en sí mismo, sino, por el contrario, ir hacia otro: intentar alcanzar en un movimiento de apertura ese otro que no soy yo" (Blanco, 25). El mero hecho de nombrar las cosas que nos han dolido, según Blanco, es el primer paso hacia la curación de ese dolor: "Nombrar, decir, designar 
sería algo más que un simple acto lingüístico: se trataría de una especie de acto casi terapéutico o mágico que permitiría drenar el dolor. La autoficción reconoce en la palabra ese poder curativo ya que, en el acto de nombrar, todo vocablo puede no solo calmar y aliviar, sino también curar" (Blanco, 101-2).

Esta filosofía la comparte plenamente Ortiz de Gondra y le lleva hasta el extremo de sentir la necesidad de "nombrar las cosas que nos han dolido" personalmente en el escenario. En su entrevista con Álvaro Vicente, menciona que en su drama Los Gondra creó el personaje de un escritor que era él, pero pensaba que ese papel lo interpretara un actor. Fue el director de esa obra, Josep María Mestres, que luego dirigiría tambíen Los otros Gondra, quien le convenció de que subiera él al escenario a interpretar el personaje. En el caso de Los otros Gondra, sin embargo, entendió claramente que él mismo debería interpretar el papel del dramaturgo Gondra:

esto lo tengo que hacer yo, más allá de que sea actor o no, lo tengo que hacer yo porque hay un dolor, una herida y una pregunta sobre si la ficción nos puede ayudar a vivir, una pregunta que tengo que hacer yo, yo de verdad en escena. [...] Al final termino convirtiéndome en un personaje de la obra que yo he creado (Vicente, Álvaro).

Para Ortiz de Gondra, una cita de la escritora y fotógrafa francesa Sophie Calle que compartió con él su amigo Sergio Blanco, le ayudó mucho a entender la relación entre la realidad y la ficción en el teatro, "Mi arte es una ficción real; no es mi vida, pero tampoco es mentira” (Vicente, Álvaro).

Ivo van Hove, director teatral belga, y participante en el Festival Grec 2019 en Barcelona, ha comentado que el teatro consiste en reunir a un grupo de desconocidos en la oscuridad para reflexionar sobre lo peor de la condición humana. Según van Hove, los maratones de teatro que presenciaban los griegos eran los precursores de los actuales festivales de teatro y veían obras sobre tragedias indescriptibles: "Era una limpieza purificadora, que luego les permitía convivir mejor. La función de esta disciplina sigue siendo la misma. Sin el teatro, la sociedad sería todavía más salvaje" (Vicente, Álex 30). Pensamos que Borja Ortiz de Gondra también tendría entre sus aspiraciones para esta obra que actuara como "una limpieza purificadora" que permitiera "convivir mejor". 


\section{Dibliografía}

》 Aizpeolea, L. R. (2019, 25 de enero). “Una iniciativa necesaria (y revisable)”. El País, p. E17.

"Anónimo. (2019). “Programa etikasi 2019”. EGK. Consejo de la juventud de Euskadi. Consultado el 3 de octubre de 2019 en https://egk.eus/htwp-content/ uploads/2019/01/dossier-etikasi.pdf

》Aramburu, F. (2018, 30 $\underline{\text { a ed. }}$ 1⿳亠丷a ed. 2016). Patria. Barcelona: Tusquets.

" Ayanz, M. (2019). “El Gondra bueno”. Volodia. Crítica. Teatro. Cambio, [en línea]. Consultado el 30 de marzo de 2019 en http://volodia.es/critica/los-otros-gondra

»Blanco, S. (2018). Autoficción. Una ingeniería del yo. Madrid: Punto de Vista Editores.

" Catalán, J. (2019, 28 de enero). “Los otros Gondra (relato vasco contemporizador)", Periodista digital, [en línea]. Consultado el 28 de enero de 2019 en https://www. periodistadigital.com/cultura/cine-y-teatro-20190128/gondra-relato-vascocontemporizador-noticia-689400272921/

»Europa Press (2019, 16 de abril). "Aparecen en Vizcaya pintadas con el PP dentro de una diana y a favor de ETA". El confidencial, [en línea]. Consultado el 15 de junio de 2019 en https://www.elconfidencial.com/espana/pais-vasco/2019-04-16/pintada-erandio-pais-vasco-pp-diana-gora-eta_1946642/

»Gárate Oronoz, A. (2019). "La hora cultural”, RTVE 24 horas. Consultado el 15 de junio de 2019 en http://www.rtve.es/alacarta/videos/la-hora-cultural/horacultural-14-01-19/4939489/\#

» Gil, L. (2018, 19 de octubre). "Rechazo unánime de los colectivos de víctimas a 'Herenegun!' por ofrecer "una visión sesgada y sin rigor»”. El correo, [en línea]. Consultado el 10 de abril de 2019 en https://www.elcorreo.com/politica/ victimas-de-eta/rechazo-unanime-colectivos-20181116141717-nt.html

» Gorospe, P. (2019, 25 de enero). “Euskadi acepta incluir a policías y otras víctimas en la asignatura de ETA”. El País, p. E17.

"Landaluze, K. (2016, 26 de abril). “Estreno de "Las huellas perdidas" en ETB2". Naiz, [en línea]. Consultado el 10 de abril de 2019 en https://www.naiz.eus/en/ hemeroteca/gara/editions/2016-04-26/hemeroteca_ articles/estreno -de-lashuellas-perdidas-en-etb2

»López Rejas, J. (2017, 13 de enero). "Borja Ortiz de Gondra: 'Sin perdón, la sangre no se secará en el País Vasco'”. El Cultural, [en línea]. Consultado el 6 de octubre de 20019 en https://elcultural.com/Borja-Ortiz-de-Gondra-Sinperdon-la-sangre-no-se-secara-en-el-Pais-Vasco

" Madina, E. (2019, 15 de febrero) “Geografía de la neutralidad”. En El País, p. 11.

»Ormazabal, M. (2019, 24 de enero). "La controversia por el relato salpica a los estudiantes". El País, p. E16.

»Ortiz de Gondra, B. (2019) Los Gondra (una historia vasca). Los otros Gondra (relato vasco). Prólogo de Eduardo Pérez-Rasilla. Madrid: Punto de Vista Editores.

»Vicente, Á. (2019, 27 de junio). “Ivo van Hove: 'Sin el teatro, la sociedad sería todavía más salvaje’”. El País, p. C30. 
"Vicente, Á. (2019, 8 de enero). "Borja Ortiz de Gondra, de los Gondra de toda la vida”, Revista Godot, [en línea]. Consultado el 14 de mayo de 2019 en http:// revistagodot.com/borja-ortiz-de-los-gondra-de-toda-la-vida

»Vidales, R. (2019, 9 de enero). "Teatro de la memoria para sanar las heridas de Euskadi”. El País [en línea].. Consultado el 20 de enero de 2019 https://elpais. com/cultura/2019/o1/og/actualidad/1547057644_638812.html 